\title{
spinifex scriptures
}

\author{
Yvette Holt
}

Poet, Writer and Photographer, Australia

\begin{abstract}
"spinifex scriptures" and "desert analysis" deconstruct through poetry and photography the post-colonial presence of Christian armour, and environmental desert rust - recycled through the economical chambers of abandonment.
\end{abstract}

Keywords: Poetry, Photography, Central Australia, Desert, Indigenous

eTropic: electronic journal of studies in the tropics publishes new research from arts, humanities, social sciences and allied fields on the variety and interrelatedness of nature, culture, and society in the tropics. Published by James Cook University, a leading research institution on critical issues facing the worlds' Tropics. Free open access, Scopus, Google Scholar, DOAJ, Crossref, Ulrich's, SHERPA/RoMEO, Pandora, ISSN 1448-2940. Creative Commons CC BY 4.0. Articles are free to download, save and reproduce. Citation: to cite this article include Author(s), title, eTropic, volume, issue, year, pages and DOI: http://dx.doi.org/10.25120/etropic.19.1.2020.3727 


\section{spinifex scriptures}

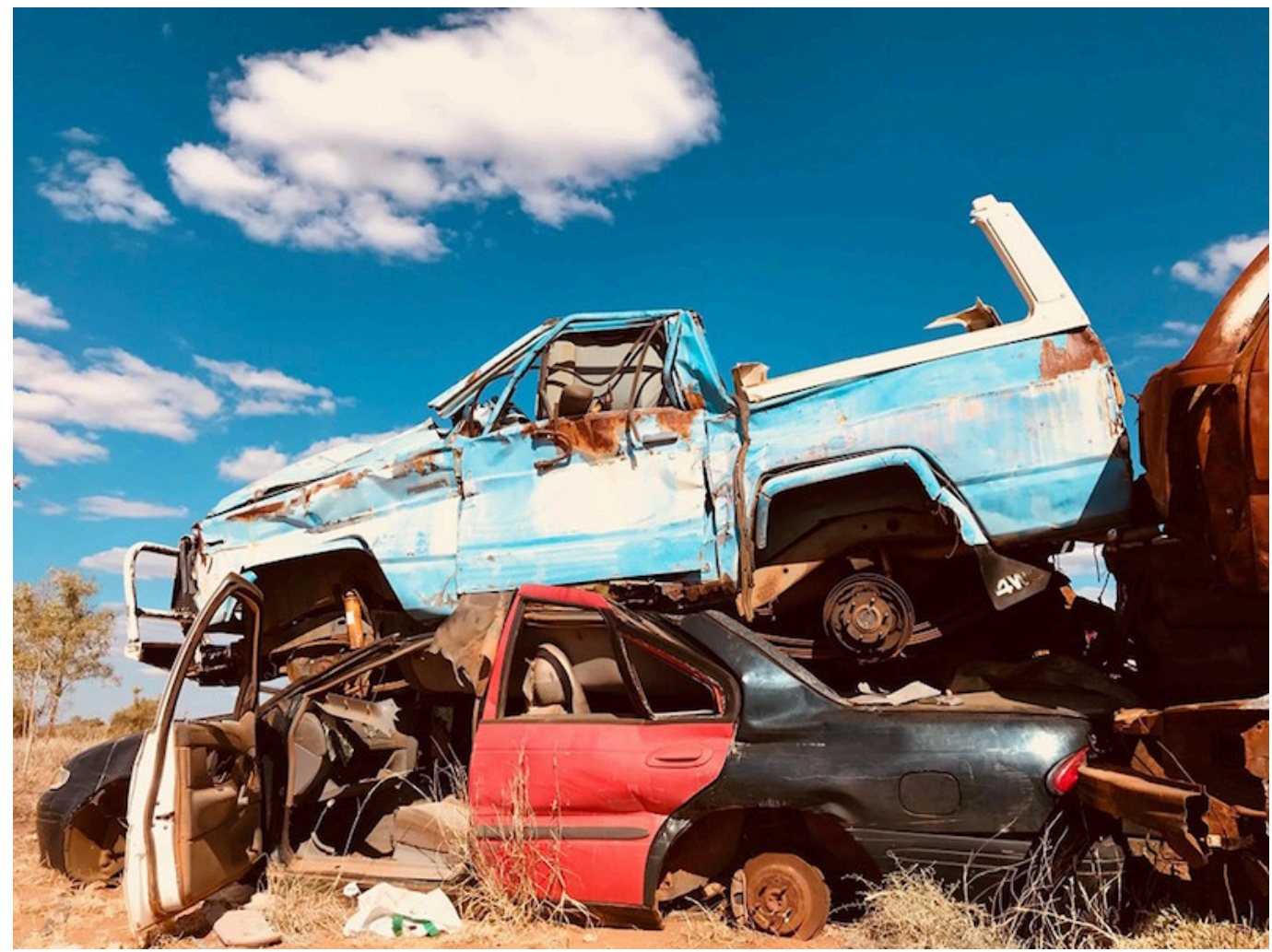

Figure 1. Old Mt Allen Pastoral Lease

old testament

desert_story

desert_sacred

desert_our_home

desert_strong

desert_food

desert_plenty

desert_songlines

desert_survival 


\author{
new testament \\ motor_car_come \\ motor_car_leak \\ motor_car_stop \\ motor_car_prickles ${ }^{1}$ \\ motor_car_burn \\ motor_car_sleep \\ motor_car_rust \\ motor_car_steel
}

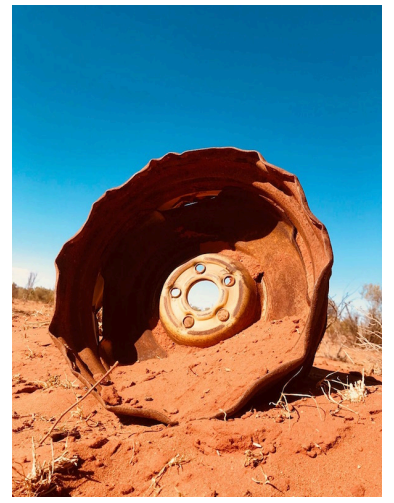

Figure 2. Tanami Highway

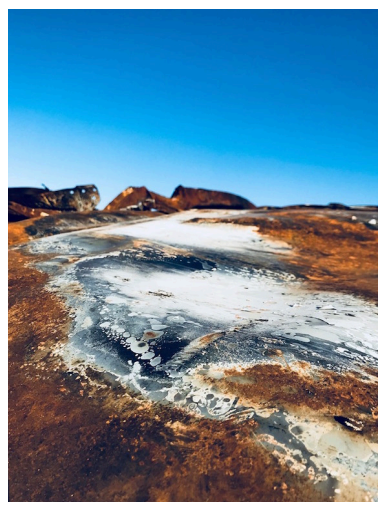

Figure 3. Yuelamu 2

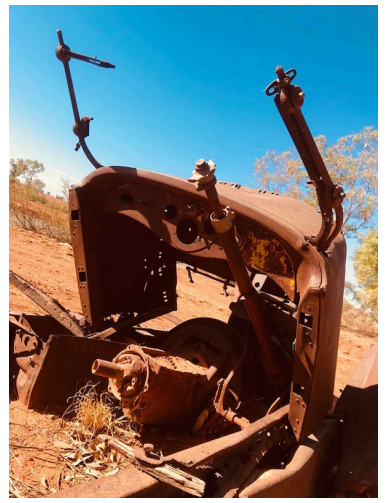

Figure 4. Titjikala 2

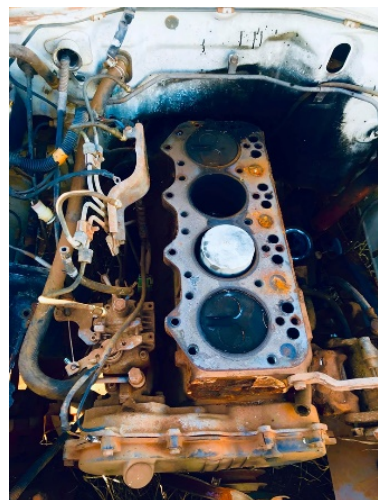

Figure 5. Yuelamu 3

\footnotetext{
${ }^{1}$ Shattering of splintered glass
} 


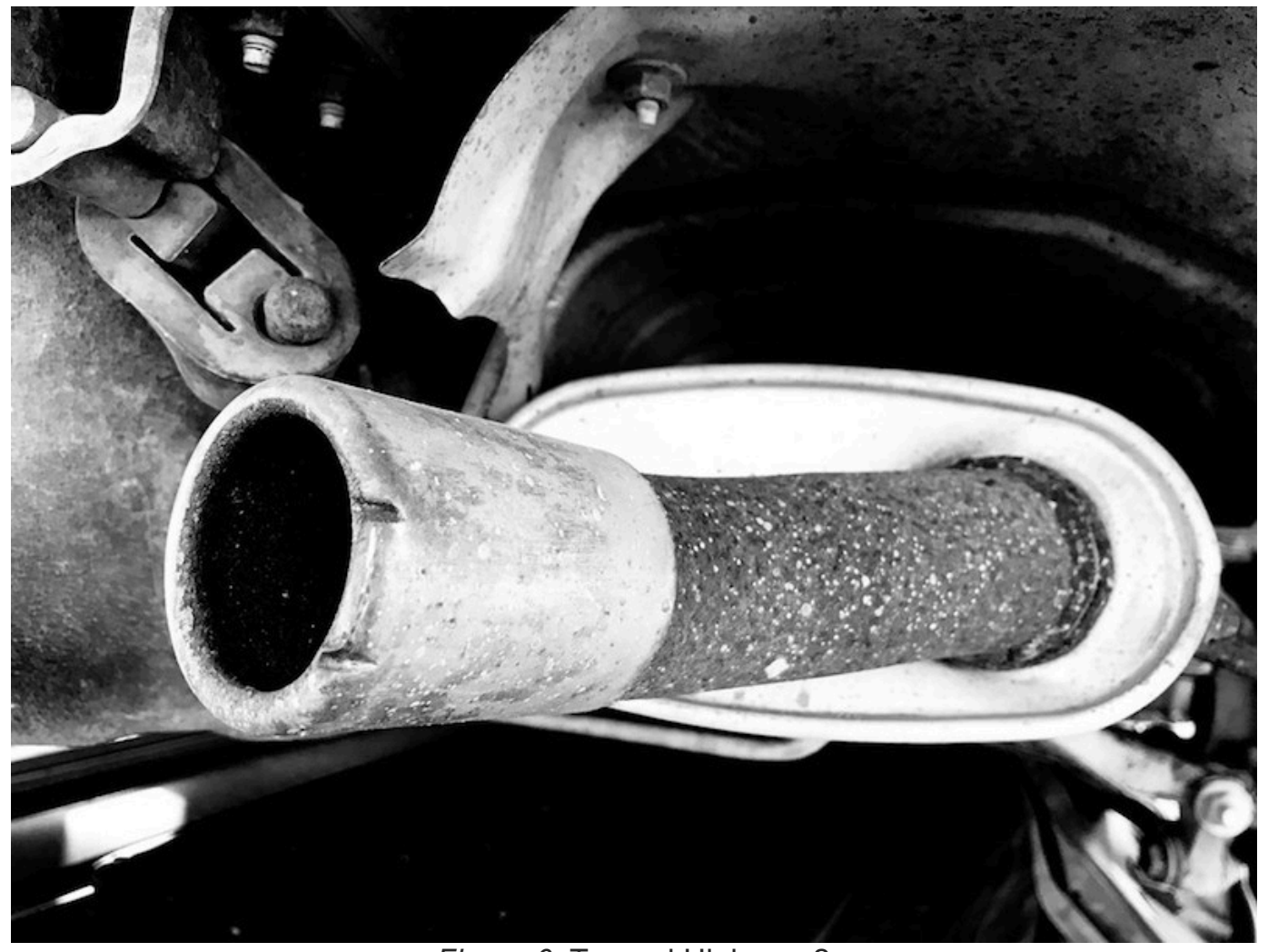

Figure 6. Tanami Highway 2

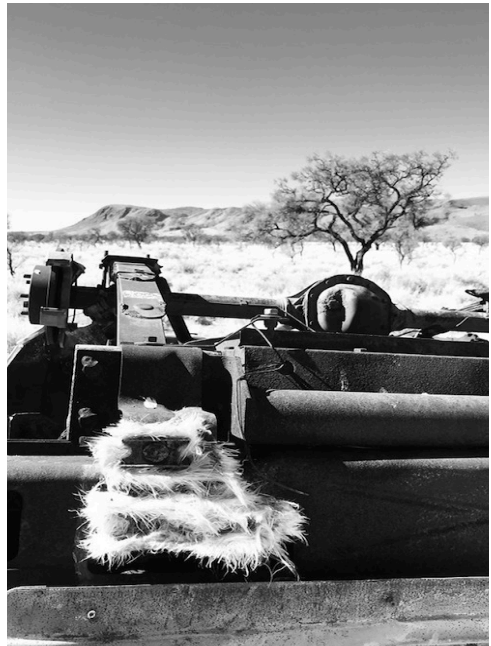

Figure 7. Santa Teresa 3

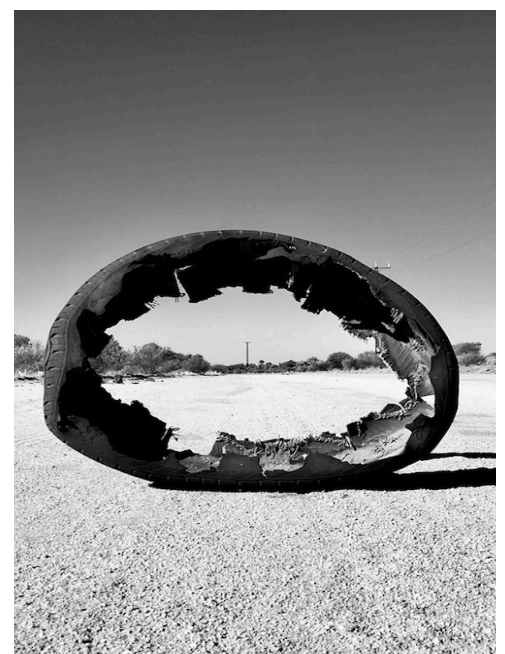

Figure 8. Tanami Highway 3

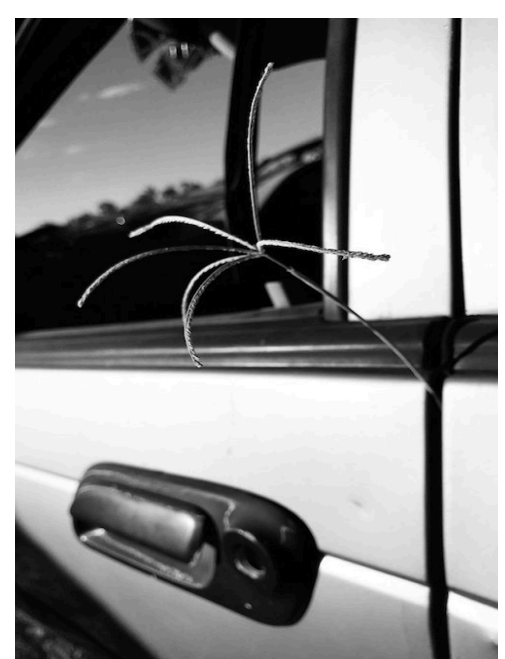

Figure 9. Yuelamu 7 


\section{desert analysis}

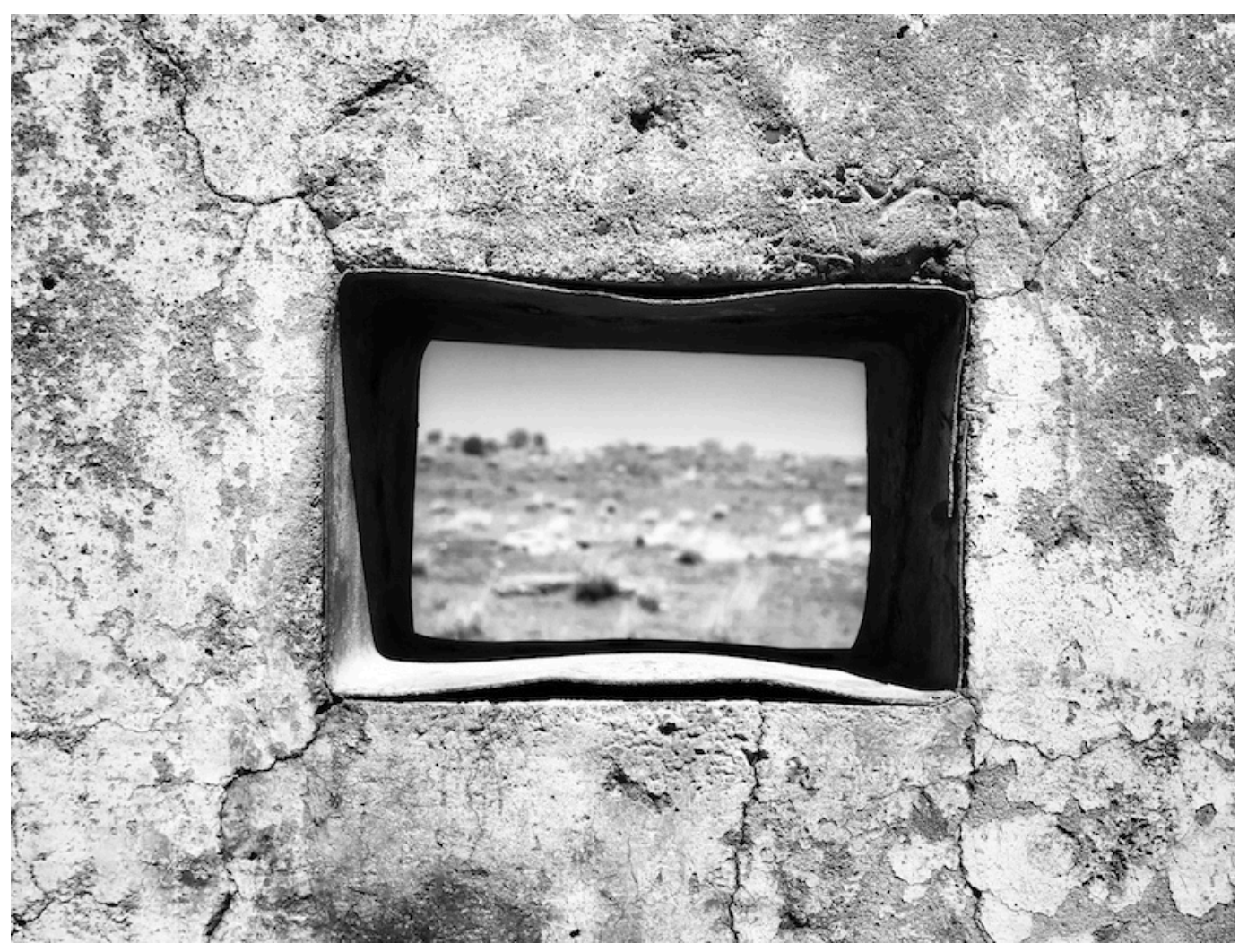

i

moon paralysis

empty skies

departing sleep

woman echoes

combing moths

one ocean at a time

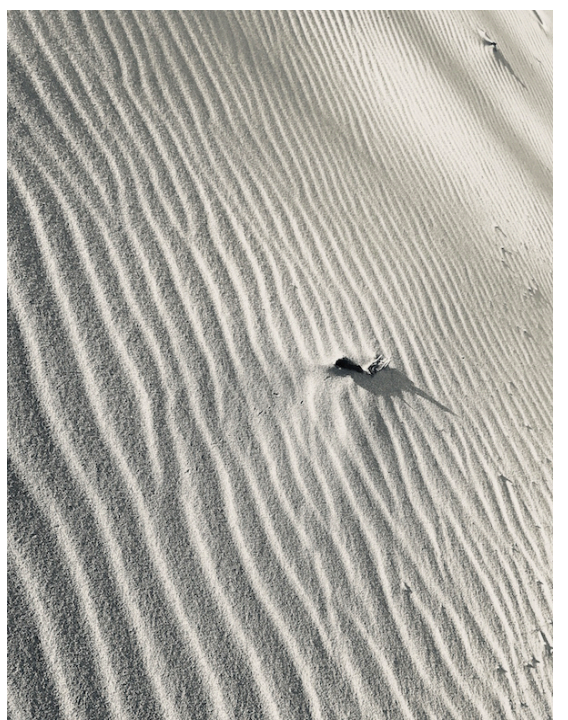


ii

over there

but not too distant

swimming mountains

speechless waters

curlew climbs

softly drowning

high above

ceramic clouds

iii

analogue tongues

borrow at midnight

moon awakens

dust forsaken

moonlight swells

rivers recede
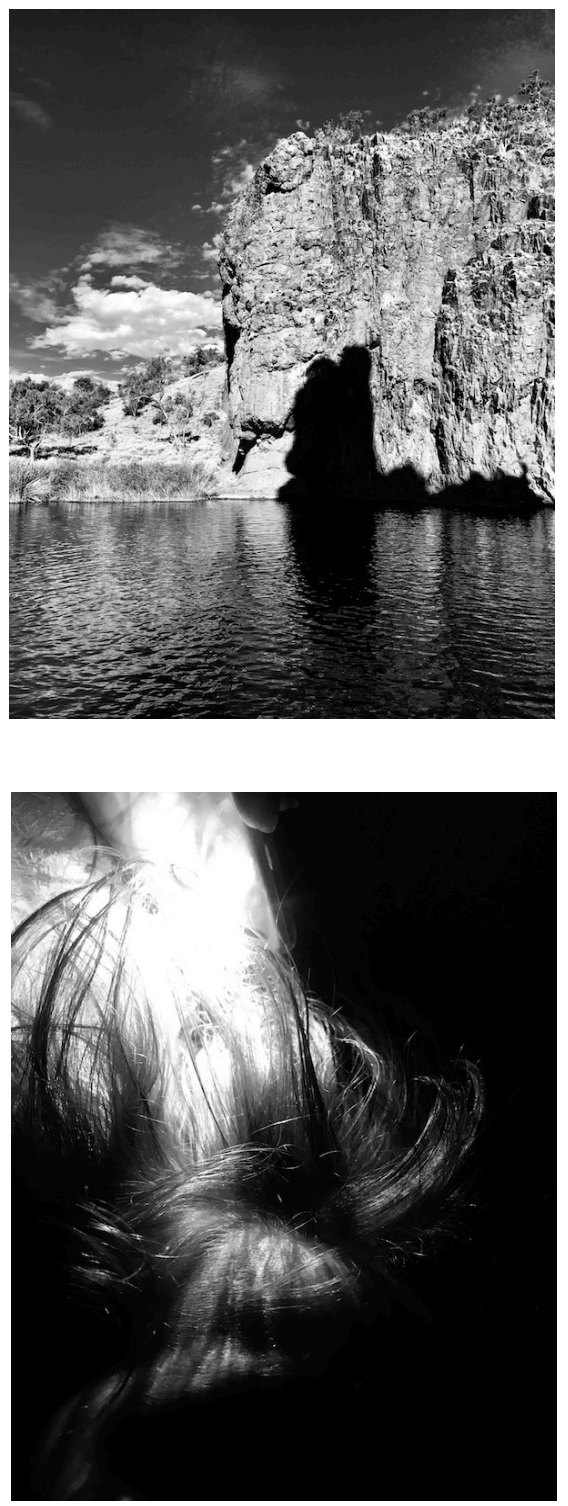

iv

woman escapes

desert simmers

beneath her stains

inhaling salt

twisting like seashells

upon a boneless floor

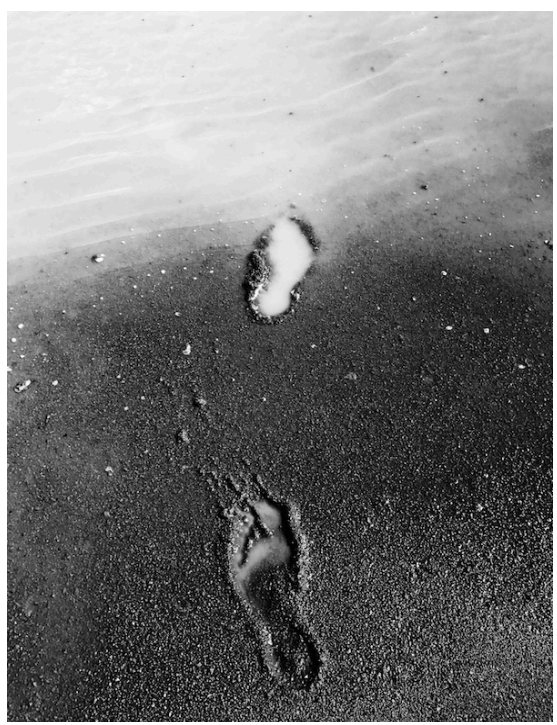




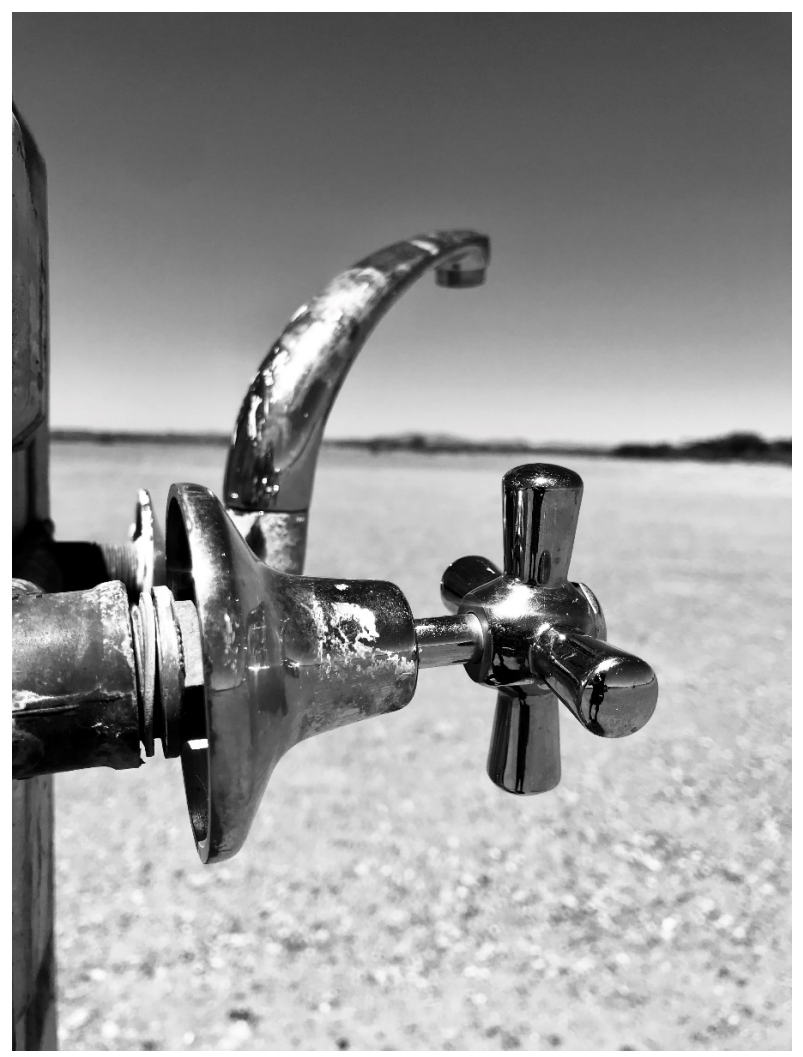

Brisbane-born Yvette Henry Holt heralds from the Bidjara, Yiman and Wakaman Nations of Queensland. A multi-award winning poet, academic, editor, and photographer of erotic desert votive imagery and landscape, she lives in the Central Deserts of remote Australia. Her debut poetry collection, Anonymous Premonition (UQP 2008), won the Queensland Premier David Unaipon Award 2005, Scanlon Prize for Poetry NSW 2008, Victorian Premier's Prize for Indigenous Writing 2008 and the RAKA Kate Challis Award 2010. In 2018 Yvette's poem, mother's native tongue, an ode to all who have a parent living with dementia, was Highly Commended for the Queensland Poetry Oodgeroo Noonuccal Prize. Yvette's expansive literary works have appeared nationally and internationally online and in print. She is the chairperson of the First Nations Australia Writers Network FNAWN. 